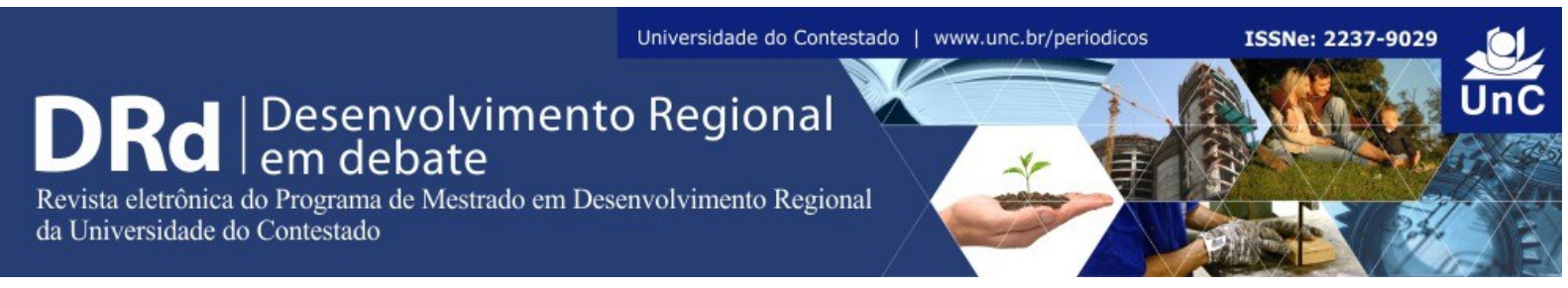

\title{
ASPECTOS DA MULTIFUNCIONALIDADE NO PLANALTO NORTE CATARINENSE: ADUBAÇÃO ORGÂNICA NO INCREMENTE DA PRODUÇÃO DE ERVA-MATE
}

Eliziane Luiza Benedetti ${ }^{1}$
Valdir Roque Dallabrida

\begin{abstract}
RESUMO
A multifuncionalidade da agricultura, como prática pós-produtivista, tem ganhado importância no mundo todo. Melhorias na qualidade do produto, preservação ambiental além da melhoria das condições de vida dos produtores, são enfatizadas nesse sistema de produção. No entanto, no Planalto Norte Catarinense esses aspectos ainda são pouco explorados, pois ainda predomina a agricultura convencional. Como uma das características marcantes dessa região é o predomínio de ervais nativos em sub-bosque da Floresta Ombrófila Mista, estudos que visem a melhoria desses sistemas com enfoque em aspectos da multifuncionalidade são fundamentais para o desenvolvimento da região. Nesse sentido, o objetivo desse estudo foi avaliar o benefício da adubação orgânica na produção da erva-mate. $O$ estudo foi desenvolvido em ervais nativos dos municípios de Canoinhas e Irineópolis em erval em mata, erval em caíva e erval em caíva aberta. Em cada tipo de erval, quatro plantas receberam adubação orgânica e quatro não receberam adubação. Observa-se que em todas as propriedades, a maior incidência de luz e a adubação aumentaram a produtividade da ervamate. Desta forma, conclui-se que a adoção de técnicas de adubação orgânica se mostrou viável para a produção de erva-mate nativa no sub-bosque da Floresta Ombrófila Mista na região do PNC, uma vez que melhorou a produtividade da erva-mate, oportunizando dessa forma a diversificação da propriedade dentro dos preceitos agroecológicos e multifuncionais.
\end{abstract}

Palavras-chave: Pós-Produtivismo. Agroecologia. Cultivo Orgânico. Desenvolvimento Regional. Ilex Paraguariensis.

\section{ABSTRACT \\ ASPECTS OF MULTIFUNCTIONALITY THE PLATEAU NORTH CATARINENSE: FERTILIZING ORGANIC TO YERBA MATE PRODUCTION}

The multifunctionality of agriculture, such as post-productivist practice has gained importance worldwide. Improvements in product quality, environmental protection as well as improving the living conditions of the producers, are emphasized in this production system. However,

\footnotetext{
${ }^{1}$ Graduação e doutorado em Agronomia, com pós-doutorado no Programa de Mestrado em Desenvolvimento Regional da Universidade do Contestado (UnC) (2015/2016), Professora do Instituto Federal de Educação, Ciência e Tecnologia de Santa Catarina (IFSC)-Campus Canoinhas. Santa Catarina. Brasil. E-mail: eliziane.benedetti@ifsc.edu.br

${ }^{2}$ Geógrafo, Doutor em Desenvolvimento Regional e docente do Programa de Mestrado em Desenvolvimento Regional da UnC. Santa Catarina. Brasil. E-mail: valdirdallabrida@gmail.com
} 
the North Plateau of Santa Catarina these aspects are still little explored because still dominates conventional agriculture. As one of the striking features of this region is the predominance of native herbal understory in the Mixed Ombrophylous Forest, studies aimed at improving these systems with a focus on multi-functionality of aspects are fundamental to the development of the region. In this sense, the objective of this study was to evaluate the benefit of organic fertilizer in the yerba mate production. The study was developed in native herbal municipalities of Canoinhas and Irineópolis in herbal in woods, herbal in caíva and herbal in open caíva. In each type of herbal, four plants received organic fertilizer and four did not receive fertilization. It is observed that in all the properties, the highest incidence of light and fertilization increased yerba mate productivity. Thus, it is concluded that the adoption of organic fertilization techniques proved feasible for the native yerba mate production in the understory of Araucaria Forest in the PNC region since improved yerba mate productivity, providing opportunities thus diversity of ownership within the agroecological and multifunctional precepts.

Keywords: Post-Productivism. Agroecology. Organic Farming. Regional Development. Ilex Paraguariensis.

\section{INTRODUÇÃO}

O território do Planalto Norte Catarinense tem sua história marcada por batalhas relacionadas à posse das terras e foi cenário do conflito conhecido como a Guerra do Contestado. Atualmente essa é a região do Estado de Santa Catarina com um dos menores índices de desenvolvimento humano. A região sempre teve na exploração da erva-mate uma das formas de sustentação econômica, sendo essa a atividade predominante até a década de 1930. Após esse período, quando a Argentina começou a produzir a erva que consumia, ocorreu uma crise no setor ervateiro. Assim, parte da população abandonou a cultura da ervamate para dedicar-se à extração e industrialização da madeira e a agropecuária. Mesmo assim, atualmente essa região é responsável pela maior parte da produção de erva-mate do Estado, no entanto, a forma de produção extrativista, na sua maioria, ainda perdura na região.

Dos ervais que ainda restam, predomina a erva-mate nativa, encontrada no sub-bosque de remanescentes da Floresta Ombrófila Mista, muitas vezes em consórcio com pastagens e criação de animais, sendo esse um diferencial para os ervais da região. Essas características estão em consonância com aspectos da multifuncionalidade da agricultura, principalmente pela preservação da mata. No entanto, algumas adaptações no manejo poderiam ser inseridos a fim de tornar essa atividade mais sustentável e rentável. A inserção de práticas agroecológicas para produção de erva-mate, contemplando a produção orgânica merece ser melhor elucidada nessa região.

Santa Catarina destaca-se pela grande produção de frango, no entanto, essa atividade gera grandes quantidades de resíduos (cama de aviário) que, se utilizados em local e em quantidades inadequadas, podem provocar problemas ambientais. Assim, sua utilização se apresenta como uma das alternativas de maior receptividade pelos agricultores, por estar presente e/ou disponíveis próximo às propriedades, a um baixo custo (COSTA et al., 2009), além de que, quando manejados adequadamente, aumentam o rendimento das culturas, a fertilidade do solo e diminuem o potencial poluidor (CHOUDHARY et al., 1996). 
Esses aspectos estimularam a realização de investigação da qual resultou o presente artigo. Assim, inicialmente, serão apresentados os aspectos teóricos que subsidiam esse estudo, como a multifuncionalidade da agricultura, produção agroecológica e orgânica e sistemas agroflorestais. A caracterização do território em estudo e da erva-mate será abordada num segundo momento; após será finalizado o texto com as discussões dos resultados e considerações.

Espera-se que esse estudo possa dar subsídio aos agricultores da região a fim de alavancar a produção de erva-mate de modo que os aspectos ambientais, sociais e econômicos sejam considerados.

\section{PROCEDIMENTOS METODOLÓGICOS}

Esse trabalho faz parte do plano de atividades de estágio pós-doutoral realizado no Programa de Mestrado em Desenvolvimento Regional (PMDR) da Universidade do Contestado (UnC - Santa Catarina - Brasil) ${ }^{3}$ e está dividido em duas partes. Inicialmente se apresenta a revisão bibliográfica com uma abordagem sobre a multifuncionalidade no meio rural, com ênfase na agricultura agroecológica, orgânica e sistemas agroflorestais, como formas de alcançar a multifuncionalidade, seguindo com a caracterização do Planalto Norte Catarinense dando destaque para aspectos da erva-mate. Finaliza-se com a apresentação e discussão dos resultados dos estudos a campo e as considerações finais.

\section{COLETAS DE CAMPO}

O estudo foi desenvolvido em dois municípios que compõe o Planalto Norte Catarinense: Canoinhas e Irineópolis. Quatro propriedades rurais foram selecionadas, com ervais nativos nas seguintes condições: (i) Erval em mata (cobertura florestal mais conservada, erval nativo, sem a presença constante de animais); (ii) Erval em caíva (cobertura florestal relativamente conservada, erval nativo, presença constante de animais, sub-bosque com presença de pastagens) e (iii) Erval em Caíva Aberta (cobertura florestal mais aberta pela ação antrópica, erval nativo, presença constante de animais, sub-bosque dominado pelas pastagens na maior parte da área) (MARQUES, 2014). Em cada tipo de erval foram selecionadas oito plantas, das quais, quatro receberam e quatro não receberam adubação. As plantas encontravam-se com brotação de 12 meses após a colheita. Selecionaram-se as com características de estrutura de copa semelhante e, após a demarcação das mesmas, as plantas que iriam receber adubo foram definidas por sorteio, eliminando-se tendências.

A partir da análise de solo, realizou-se a recomendação de adubação para obtenção da dose do adubo a ser aplicada. Para o suprimento dos nutrientes utilizou-se adubo orgânico (cama de frango), disponível facilmente na região. A dose da adubação foi parcelada em duas aplicações (efetuada em setembro de 2015 e janeiro de 2016) em superfície ao redor da

\footnotetext{
${ }^{3} \mathrm{O}$ tema dos estudos no Estágio Pós-Doutoral foi Contribuição ao desenvolvimento territorial através da avaliação nutricional de solos e plantas de ervais nativos, como estímulo à produção orgânica sustentável, no Planalto Norte Catarinense, onde os autores deste texto são, respectivamente, orientada e orientador. O estágio foi viabilizado por bolsa de pós-doutorado PNPD-CAPES, concedida ao PMDR da UnC no período de julho/2015 a junho/2016.
} 
planta. As plantas adubadas também receberam uma dose de calcário para suprir cálcio e magnésio, conforme recomendação para a cultura da erva-mate (SANTIN; BENEDETTI; REISSMANN, 2015). Após três meses da última adubação realizou-se a colheita para mensuração da produtividade.

\section{MULTIFUNCIONALIDADE DA AGRICULTURA: CONCEPÇÃO E IMPLICAÇÕES}

Com o advento das práticas pós-produtivistas (ILBERY e BOWLER, 1998; WILSON, 2001; EVANS; MORRIS; WINTER, 2002; LÓPEZ, 2005;), houve o estímulo às novas práticas no meio rural, caracterizada pela multifuncionalidade.

De maneira geral, a noção de multifuncionalidade da agricultura pode ser entendida como um novo olhar sobre a agricultura familiar, que permite analisar a interação entre famílias rurais e territórios, considerando os modos de vida das famílias em sua integridade, e não apenas seus componentes econômicos (CAZELLA; BONNAL; MALUF, 2009). A noção incorpora a provisão, por parte dos agricultores, de bens públicos relacionados com o meio ambiente, a segurança alimentar e o patrimônio cultural (MALUF, 2002). A multifuncionalidade se apresenta como uma nova perspectiva para o meio rural. Esse ambiente não é mais visto somente como local para produzir alimentos e, sim, um local onde diversas atividades, relacionadas ou não ao setor, podem ser inseridas. A inserção desses novos agentes, como protetores do patrimônio cultural e do meio ambiente, assim como responsáveis pela promoção da segurança alimentar, traz um novo sentido ao rural, sendo que esses atores são percebidos por desempenharem uma função social, não apenas uma função comercial e ou econômica.

Essa noção surge efetivamente na Europa indo de encontro às práticas e políticas voltadas à produtividade e ao crescimento econômico. O modelo de crescimento adotado e fomentado pela Comunidade Econômica Europeia, no pós Segunda Guerra Mundial, provocou o esvaziamento de algumas áreas rurais, o desgaste dos recursos naturais, o aumento da produção e o alto custo, com medidas de apoio à agricultura modernizada. Nesse contexto, a noção de multifuncionalidade se desenvolveu na Europa na década de 1990, sendo a França o país que encaminhou os primeiros dispositivos institucionais para fomentá-la.

No Brasil, a partir da década de 90 iniciaram os debates sobre a multifuncionalidade da agricultura, durante a realização da Conferência das Nações Unidas sobre Meio Ambiente e Desenvolvimento - Eco 92. A partir da Eco 92, a multifuncionalidade foi caracterizada como o reconhecimento pela sociedade de funções sociais, ambientais, econômicas ou culturais, não diretamente produtivas ou não mercantis e associadas à atividade agropecuária. No entanto, no Brasil, ainda são raros os instrumentos de uma política de multifuncionalidade. De acordo com Sabourin (2008), na América Latina, a principal medida de tipo multifuncionalidade já experimentada consiste na remuneração de serviços ambientais, como o sequestro de $\mathrm{CO}_{2}$.

Concorda-se com Cazella e Mattei (2002) de que não se trata de um novo modelo a ser construído, mas de uma forma de existência real de unidades familiares de produção agrícola. Segundo os autores, essas novas funções que vem sendo atribuídas à agricultura familiar já eram realizadas pelos agricultores. $\mathrm{O}$ que muda é o atual reconhecimento das mesmas, e a 
valorização de outras dimensões além da produtivista. Ou seja, nada mais que um novo olhar para um velho sistema.

A adequada caracterização da agricultura multifuncional para seu adequado reconhecimento deve ser priorizada. A identificação de aspectos positivos e potencialidades, como por exemplo, a conservação do meio ambiente, só é possível de serem reconhecidos quando a análise não for meramente econômica. É o que destaca Cazella (2003) em estudo realizado em Santa Catarina, no qual identificou como funções da agricultura multifuncional, a promoção da segurança alimentar das famílias, a manutenção da paisagem rural, a conservação dos recursos naturais e a inclusão social das famílias. Desta forma, o conceito de multifuncionalidade vai além da geração de renda através da produção sustentável de alimentos, uma vez que insere os aspectos sociais e culturais das famílias rurais.

Grandes são os desafios para implementação da agricultura multifuncional pelas comunidades rurais. As novas missões que queremos confiar à agricultura competem umas com as outras: a multifuncionalidade não implica, por natureza, que a harmonia prevaleça, e estas diversas funções da agricultura não são imediatamente ou facilmente conciliáveis (RÉMY, 2010). Desta forma, o estímulo à inserção desse modelo pelas famílias e ou comunidades deve ser adaptado a cada realidade.

Nesse sentido, observa-se grande variedade de funções da agricultura que a traduzem para a multifuncionalidade, as quais podem estimular a permanência das famílias no meio rural. Observando as potencialidades e pensando em sugestões para multifuncionalidade da agricultura no território do Planalto Norte Catarinense, será abordado mais profundamente a produção agroecológica e orgânica de alimentos aliado aos sistemas agroflorestais.

\section{AGROECOLOGIA}

O declínio na qualidade de vida rural e a degradação dos recursos naturais associados à agricultura pós Revolução Verde, impulsionou a discussão sobre o desenvolvimento sustentável neste meio, tornando a produção agrícola não apenas uma questão técnica, mas um processo condicionado por dimensões ambientais, sociais, culturais, políticas e econômicas, que devem ser compatibilizadas em agroecossistemas sustentáveis (ALTIERI, 2009).

O desafio imediato da nossa geração é transformar a agricultura industrial e iniciar uma transição para sistemas alimentares que não dependam do petróleo, que sejam biodiversos, resilientes às mudanças climáticas e, ao mesmo tempo, fortaleçam a produção doméstica. Desta forma, a agroecologia se apresenta como a alternativa mais viável para gerar sistemas capazes de produzir conservando, além de prestar serviços ambientais (ALTIERI; NICHOLLS, 2011).

A Agroecologia fornece os princípios básicos para o estudo e tratamento de ecossistemas tanto produtivos quanto preservadores dos recursos naturais, e que sejam culturalmente sensíveis, socialmente justos e economicamente viáveis (ALTIERI, 1987). Porém, restaurar a saúde ecológica não é o único objetivo da agroecologia. A manutenção dos sistemas tradicionais de conhecimento é relevante para a agroecologia, desta forma, consideram-se os saberes locais nesse contexto. 
Atualmente é visível a diminuição da população rural tanto do Brasil, passando de 24,4\% em 1991 para 15,6\% em 2010 (MAIA; BUAINAIN, 2015), como do mundo, onde atualmente a população rural corresponde a $46 \%$ do total, com expectativa de diminuir para $34 \%$ em 2050 (ONU, 2015). Os problemas de sucessão nas pequenas propriedades podem ser superados com o estímulo à produção agroecológica, desde que: (i) se incorporem estratégias de desenvolvimento que melhorem a qualidade de vida dos pequenos agricultores, com o desenvolvimento de estratégias de subsistência ecologicamente fundamentadas; (ii) aumentem a produtividade da terra daqueles agricultores que competem no mercado, através do planejamento e promoção de tecnologias de baixo uso de insumos, que reduzam os custos de produção e promovam a geração de renda e trabalho, através do planejamento de tecnologias apropriadas que aumentem o valor agregado do que é produzido dentro das pequenas propriedades, particularmente na área de processamento de alimentos (ALTIERI, 2009).

Assim, se insere o aproveitamento dos saberes locais. Aquelas áreas rurais que mantém uma reserva de formas econômicas baseadas na agricultura tradicional podem ser o melhor espaço para aproveitar as novas oportunidades econômicas (MIOR, 2010). Observa-se nesse sentido a oportunidade para a inserção da agricultura agroecológica, uma vez que os processos de mudança rural não devem ser vistos como determinados unicamente pelas forças presentes na globalização do sistema alimentar. Seu estudo deve incluir os processos de reestruturação rural, que envolve as dinâmicas sociais e econômicas regionais (MARSDEN et al., 1990).

\section{AGRICULTURA ORGÂNICA}

A agricultura orgânica é um sistema holístico de gestão da produção que fomenta e melhora a qualidade do agroecossistema (em particular, a biodiversidade), dos ciclos biológicos e da atividade biológica do solo. Os sistemas de produção orgânica se baseiam em normas de produção específicas e precisas, cuja finalidade é obter agroecossistemas que sejam sustentáveis dos pontos de vista social, ecológico, técnico e econômico (FAO/OMS, 2001).

Assim sendo, a agricultura orgânica é um sistema de produção comprometido com a saúde, a ética e a cidadania do ser humano, visando contribuir para a preservação da vida e da natureza. Busca utilizar de forma racional os recursos naturais, empregando métodos de cultivos tradicionais e as mais recentes tecnologias ecológicas (PENTEADO, 2001). Contendo as características do economicamente viável, ambientalmente correto e socialmente justo, a agricultura orgânica assume papel fundamental na criação de condições para a permanência do pequeno agricultor no seu ambiente de negócios (CAPORAL; COSTABEBER, 2007).

A agricultura orgânica preenche os dois componentes das políticas ligadas à noção de multifuncionalidade. No primeiro, o econômico e social, pela criação do valor agregado e pela geração de empregos. No segundo, o ambiental e territorial, já que a agricultura orgânica tem um impacto positivo sobre o conjunto dos componentes do meio ambiente e sobre a construção de redes ou arranjos produtivos locais que contribuem para a conformação ou consolidação de um território (SCHIMIDT, 2003).

A melhoria da renda da população reflete em maiores cuidados com a saúde e questões nutricionais. Isso impulsionou o mercado dos orgânicos. No ano de 2012, aproximadamente, 
43,1 milhões de hectares encontravam-se sob manejo orgânico no mundo, com 2 milhões de produtores envolvidos nessa atividade (WILLER; LERNOUD, 2014). No entanto, apesar do interesse pela alimentação orgânica estar ainda restrito a uma pequena parcela da população, a crítica ao uso dos agrotóxicos e a busca de alimentos saudáveis vêm ganhando espaço entre agricultores familiares e consumidores.

Em 2013, a América Latina possuía 6,6 milhões de hectares produzindo organicamente, o que corresponde a $15 \%$ da produção mundial, no entanto, esse sistema de produção ocupa apenas $1,1 \%$ das terras agricultáveis da região. A participação do Brasil na produção orgânica ainda é incipiente, uma vez que o país destina apenas 0,7 milhões de hectares para esse tipo de produção (WILLER; LERNOUD, 2014). Mesmo assim, observa-se um crescimento na adesão dos produtores ao mercado de orgânicos. Entre janeiro de 2014 e 2015, houve um aumento de 51,7\%, sendo que a área de produção orgânica no Brasil já chega a quase 750 mil hectares. No entanto, a região Sul possui a menor área com produção orgânica no país, ocupando 37,6 mil hectares (MAGALHÃES, 2015).

Santa Catarina possui cerca de 6,2 milhões de habitantes, dos quais cerca de $16 \%$ vivem no meio rural (IBGE, 2010). Nesse estado a economia agrícola está baseada na pequena propriedade de agricultura familiar, a qual representa $87 \%$ dos estabelecimentos e ocupa $44 \%$ da área e $82 \%$ da população ativa no meio rural (IBGE, 2010).

Dentre as justificativas, por parte dos produtores, para cultivar orgânicos destacam-se sair do veneno, opção de vida, custos mais baixos e obter mais qualidade, melhorar a qualidade de vida, ter acesso ao mercado, aceitação no mercado, saúde do consumidor, conforme foram apontadas em estudo de Schimidt (2003). Como visto, a agricultura orgânica vem ganhando espaço no meio rural e se destacando como uma das alternativas de geração de renda para pequenos agricultores.

Mesmo com todo esse panorama vantajoso ao produtor de orgânicos, na prática alguns problemas ainda dificultam sua permanência nessa atividade. A falta de informação e assistência técnica eficaz para atender às demandas desse setor produtivo e a defasagem em pesquisas técnicas para solucionar problemas básicos, fazem com que o produtor de orgânicos muitas vezes fique desamparado.

\section{SISTEMAS AGROFLORESTAIS}

Os sistemas agroflorestais (SAF) são, em essência, sistemas de uso da terra que integram espécies perenes lenhosas com culturas agrícolas e ou pecuária, em arranjos espaciais e temporais (MAY; TROVATTO, 2008). Assim, há uma grande diversidade de combinações e possibilidades sob a designação de sistemas agroflorestais que diferem quanto aos arranjos estruturais (espacial e temporal), fisionomia, composição florística, manejo do sistema, aspectos ecológicos e características socioeconômicas predominantes (ENGEL, 1999; MAY; TROVATTO, 2008).

Vários são os benefícios desse tipo de cultivo, ao otimizarem o uso da terra e proporcionar simultaneamente benefícios biológicos e socioeconômicos, os SAF são apontados como sistemas sustentáveis promissores para solução de problemas no uso dos recursos naturais (NAIR, 2007). 
Os benefícios socioeconômicos reconhecidos decorrem principalmente da alternância e diversificação da produção, do (re)aproveitamento dos recursos intrínsecos aos sistema e do maior envolvimento dos agricultores com o sistema de produção (NAIR, 2007; YAMADA; GHOLZ, 2002; MAY; TROVATTO, 2008).

Considerando as características da região do PNC, observa-se que alguns sistemas agroflorestais estão presentes na paisagem, como, por exemplo, a ocorrência de erva-mate no sub-bosque da Floresta Ombrófila Mista (FOM), com pastagem e criação de animais (Figura 1), caracterizando um sistema silvipastoril.

Figura 1 - Sistema silvipastoril

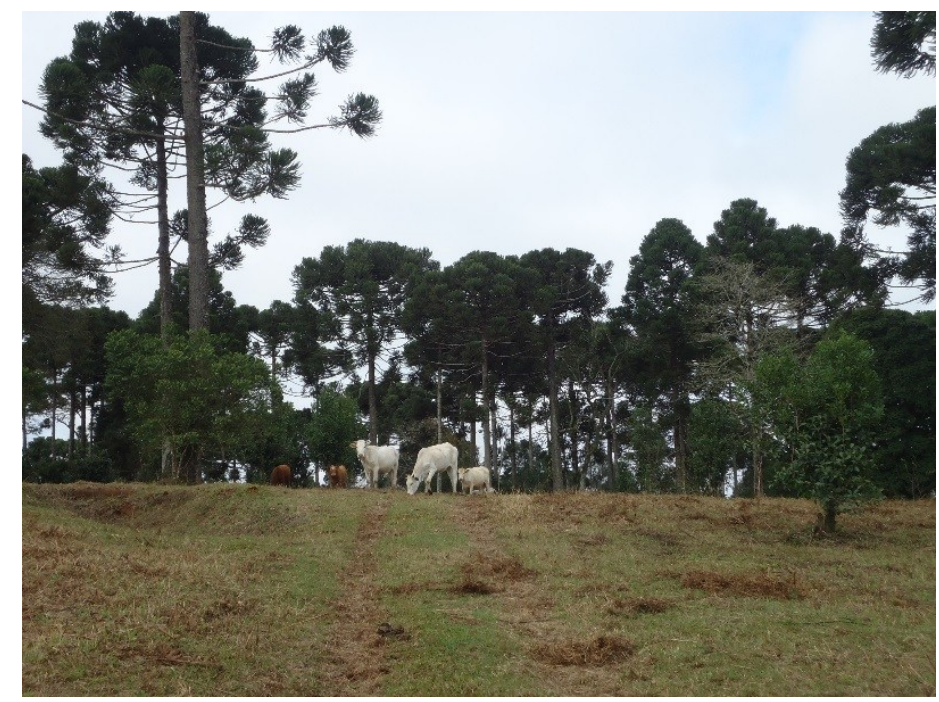

Fonte: Foto dos autores (2016)

Apesar dos reconhecidos benefícios proporcionados pelos SAF, o setor enfrenta inadequada disseminação do conhecimento, falta de incentivos, restrições legais e a falta de coordenação entre setores governamentais para os quais os SAF contribuem: agricultura, silvicultura, desenvolvimento rural, meio ambiente e comércio (FAO, 2013).

De acordo com Altieri e Nicholls (2011) os SAF aumentam a multifuncionalidade da agricultura em muitas comunidades, contribuindo não só para a soberania alimentar e produtiva de milhares de famílias, mas também para a economia comunitária e a proteção da biodiversidade. Esses sistemas têm demonstrado ser resilientes a eventos climáticos extremos. Além de que a propagação de SAF de base agroecológica pode ter impacto positivo na subsistência, resiliência e soberania das comunidades agrícolas. O sucesso vai depender do uso de um conjunto de práticas que, além da diversificação de produtos, favoreçam o melhor uso dos recursos locais e valorizem o capital humano por meio de capacitações (ALTIERI; NICHOLLS, 2011). 


\section{MULTIFUNCIONALIDADE: INSPIRAÇÕES PARA O PLANALTO NORTE CATARINENSE}

Algumas características do Estado, como a ocupação e colonização do território marcado por uma estrutura fundiária em pequenas unidades de produção familiar (com área média estimada em 15,8 hectares), características edafo-climáticas e topográficas especiais e por uma distribuição espacial bem equilibrada da população e das atividades produtivas, de acordo com Vieira et al. (2009) distinguem o Estado em relação aos demais. Essas características são determinantes para o incentivo à multifuncionalidade na região.

O relevo predominante do Estado é bastante acidentado, com restrições tecnológicas e ambientais ao cultivo. Essas condições favorecem o desenvolvimento de uma agricultura mais intensiva em mão de obra e de maior sustentabilidade. Além disso, o estado de Santa Catarina possui vantagens comparativas aos demais estados no que se refere à diversidade e à qualidade de clima e solo, à presença da mão de obra familiar e à existência de centros urbanos importantes e bem distribuídos, os quais favorecem o desenvolvimento de mercados regionais (ZOLDAN; MIOR, 2012).

No Território do Planalto Norte Catarinense, assim como nos municípios de Canoinhas e Irineópolis, raros são os estudos de caracterização da agricultura familiar, assim como das práticas e do potencial que a agricultura multifuncional, com ênfase na produção orgânica, possui na região.

\section{CARACTERIZANDO O PLANALTO NORTE CATARINENSE}

O Planalto Norte Catarinense é composto pelos municípios de Bela Vista do Toldo, Campo Alegre, Canoinhas, Irineópolis, Itaiópolis, Mafra, Major Vieira, Monte Castelo, Papanduva, Porto União, Rio Negrinho, São Bento do Sul e Três Barras, conforme Mapa 1. O estudo estará focado num recorte territorial menor, os municípios que compõem a Associação dos Municípios do Planalto Norte Catarinense (AMPLANORTE) ou Território da Amplanorte (TAM), do qual não participam três municípios: Campo Alegre, Rio Negrinho e São Bento do Sul. A população total estimada para os municípios da Amplanorte em 2015 é de 236.995 habitantes, com Índice de Desenvolvimento Humano Municipal (IDHM) médio de 0,718 e valor do rendimento nominal mediano mensal per capita - Rural de R $\$ 408,51$ (IBGE, 2010). Este território é caracterizado pelos menores IDH do Estado, com 2,70 \% da população em condição de extrema pobreza (com renda per capita mensal menor de $\mathrm{R} \$ 70,00$ ) (PAWLOWYTSCH, 2014). 
Mapa 1- Localização dos Municípios do Planalto Norte Catarinense

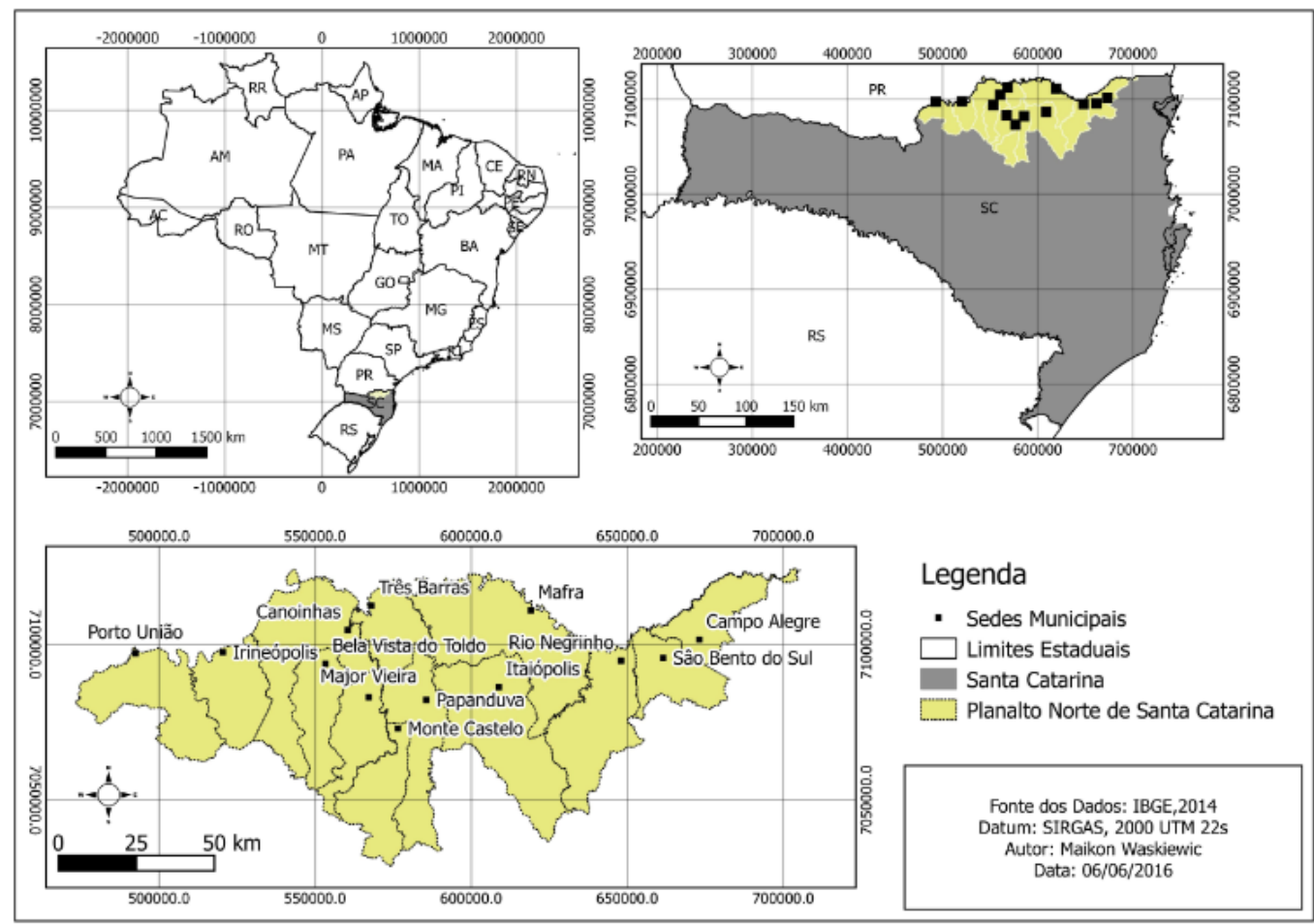

Fonte: IBGE. Elaboração: Maikon Waskiewic (2016)

No recorte territorial em referência, predomina uma matriz produtiva que não contribui para um processo de desenvolvimento territorial sustentável, nos aspectos social, econômico, cultural e ambiental, pois, como ocorre em geral, sustenta-se em práticas produtivistas, com destaque para a atividade agrícola, o que resulta na produção de commodities, a exemplo do tabaco, soja, milho e produtos da monocultura silvícola, neste caso, pela presença regional de indústrias de papel e celulose (DALLABRIDA; BENEDETTI; TOMPOROSKI, 2016). A economia dos municípios que compõem o Planalto Norte Catarinense, é predominantemente vinculada à agricultura e, secundariamente, à indústria. As atividades industriais são voltadas ao beneficiamento da madeira e processamento de ervamate, responsáveis pela maior parcela da movimentação econômica regional (SANTA CATARINA, 2005).

Uma das principais riquezas econômicas do Planalto Norte Catarinense é produção e transformação da erva-mate. A ocupação inicial deste ambiente teve como elemento central a presença de ervais nativos, sendo a exploração destes, um dos elementos chaves na formação da paisagem desta região (SOUZA, 1998).

A produção de erva-mate predominante nessa região provém das caívas (MARQUES, 2014), denominação regional no PNC para remanescentes da Floresta Ombrófila Mista com diferentes densidades arbóreas, cujos estratos herbáceos são compostos por pastagens nativas ou naturalizadas, extensivamente pastejada (HANISCH; MARQUES; BONA, 2009).

As caívas são importantes formações florestais secundárias, cujos recursos devem contribuir para o desenvolvimento rural e a conservação ambiental na região do PNC. Elas ocupam em torno de 70.000 hectares, correspondente a aproximadamente $13 \%$ do território 
do PNC (HANISCH et al., 2010). Nesse território as formas de intervenção são caracterizadas pela exploração predatória dos recursos naturais, em especial da vegetação nativa da Mata Atlântica, inicialmente com atividades de exploração madeireira e mais tarde com a exploração industrial da erva-mate.

Algumas alternativas para o desenvolvimento da agricultura familiar da região, no enfoque multifuncional, já foram apresentados. Destaque se dá aos trabalhos de Petrentchuk (2015) e Martins (2015) os quais abordam novas possibilidades para o desenvolvimento da agricultura familiar no âmbito da multifuncionalidade, como a erva-mate e plantas medicinais.

Entre $35 \%$ a $45 \%$ dos solos desse território são cobertos pela FOM, em diversos estágios de regeneração (SCOLARO; TABASCO, 2016). Uma parte dessas áreas é protegida pela legislação como Áreas de Preservação Ambiental, no entanto, parte delas poderiam ter novos usos, por meio de um manejo florestal sustentável, sendo que a presença da araucária e da erva-mate representa uma das alternativas possíveis (PETRENTCHUK, 2015).

Observa-se que esse território apresenta potencialidades para superação de práticas produtivistas. A melhoria e ou ampliação dos ervais nativos, integrados aos remanescentes florestais, se apresenta como uma alternativa viável para explorar essas áreas de forma sustentável e gerar renda ao produtor. Para que esse tipo de exploração seja sustentável, algumas práticas agrícolas devem ser efetuadas. Dentre elas, a reposição nutricional é imprescindível para que não ocorra o empobrecimento do sítio, nem o comprometimento da sustentabilidade da floresta, como observado em propriedades da região (Figura 2), onde o produto de interesse comercial (folhas) foi perdido, provavelmente por deficiência nutricional.

Desta forma, a utilização de adubação orgânica, se apresenta como uma alternativa para superar essas condições. A melhoria da fertilidade do solo, pela adição de nutrientes, aumenta a aeração e a disponibilidade de água no solo, favorecendo a infiltração e a retenção, regulando a temperatura do solo, evitando a compactação e auxiliando no controle dos processos erosivos (KIEHL, 1985).

Figura 2 - Erva-mate nativa com queda acentuada de folhas
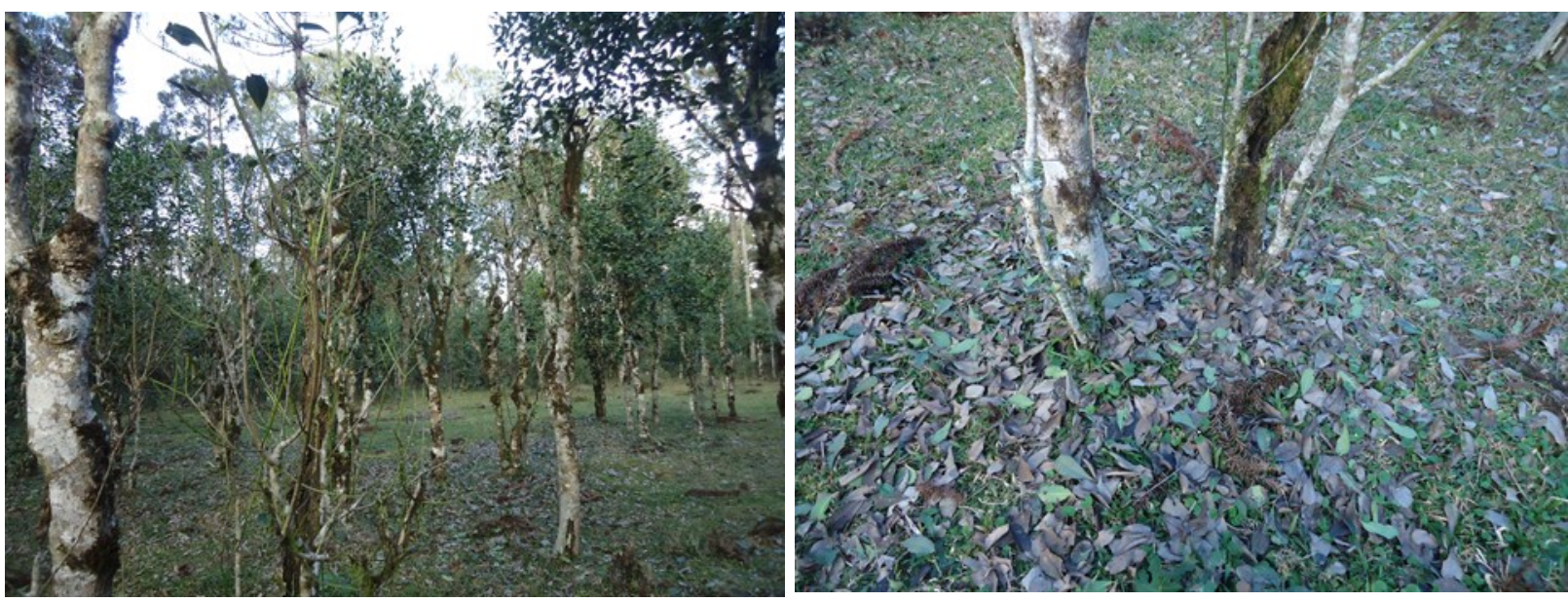

Fonte: Foto dos autores (2016)

DRd - Desenvolvimento Regional em debate (ISSNe 2237-9029) 
Levando em consideração os aspectos históricos e produtivos da região, a exploração sustentável da erva-mate, focada nos aspectos multifuncionais (englobando a agroecologia, produção orgânica e sistema agroflorestal) se apresenta como uma alternativa para geração de renda e permanência dos agricultores na propriedade e sustentabilidade do sistema.

\section{A ERVA-MATE}

A erva-mate pertence ao gênero Ilex da família Aquifoliácea e espécie paraguariensis. É uma espécie perene, com porte arbóreo e grande longevidade, podendo alcançar mais de cem anos de idade. Dentre as várias peculiaridades, sua adaptação tanto a pleno sol quanto ao sombreamento tem chamado a atenção.

É uma espécie clímax tolerante à sombra, que cresce naturalmente nas associações mais evoluídas dos pinhais (CARVALHO, 2003), mas pode ser cultivada a pleno sol. Isto é possível pelo fato da planta apresentar estômatos apenas na região abaxial das folhas, classificando-a no grupo de espécies que evitam a sombra (RAKOCEVIC; MEDRADO; TAKAKI, 2003; RAKOCEVIC et al., 2011). Como a erva-mate desenvolve-se tanto em condições de sombra quanto de sol, seu sistema de produção pode ser em monocultura (PICCOLO, GALANTINI e ROSELL, 2004) e sistemas agroflorestais (EIBL et al., 2000; DEDECEK, PHILIPOVSKY e MEDRADO, 2003; RAKOCEVIC et al., 2008). Em Santa Catarina, há mais de uma década, cerca de $80 \%$ da produção de erva-mate ainda eram provenientes de ervais nativos (DA CROCE, 2000).

No entanto, há consideráveis questionamentos a respeito da qualidade do produto entre os diferentes sistemas de cultivo. Atualmente, ainda perdura a ideia de que, para chimarrão, a erva-mate a pleno sol é mais amarga que a sombreada. No entanto, Rakocevic et al. (2008) constataram o contrário, obtendo menor amargor em folhas de plantas cultivadas a pleno sol quando comparada às sombreadas.

Quando se realizam colheitas, sejam agrícolas ou florestais, ocorre a exportação de nutrientes do local da produção. A contínua exportação de nutrientes por meio da colheita reduz a capacidade produtiva do sítio e pode desestabilizar o ecossistema, comprometendo a produtividade dos futuros ciclos da cultura (REIS; BARROS, 1990). A quantidade de nutrientes exportada de um ecossistema pela exploração florestal é determinada pela interação de concentrações, proporções entre os componentes da biomassa e a intensidade da exploração (BAGGIO; CARPANEZZI, 1997). Em ervais de alta produtividade com adequada nutrição e colhidos a cada 24 meses exportaram $263 \mathrm{~kg} / \mathrm{ha}$ de N, 10,2 kg/ha de P e $141 \mathrm{~kg} / \mathrm{ha}$ de K (SANTIN; BENEDETTI; REISSMANN, 2015), essas quantidades de nutrientes devem ser repostos ao sistema para a manutenção da sustentabilidade produtiva do sítio, sendo que a adubação orgânica é uma alternativa viável para sua reposição.

Mesmo sendo econômica e culturalmente importante na Região Sul do Brasil, a ervamate apresentou queda acentuada da produtividade nas últimas duas décadas (IBGE, 2015). No século passado o Brasil era um grande exportador de erva-mate para a Argentina (LAGIER, 2008), mas tornou-se o segundo maior importador deste produto daquele país (MONTECHIESI, 2008). Um dos motivos são os baixos investimentos em pesquisa e a exaustão nutricional do solo e da planta pelos longos anos de colheita sem reposição dos nutrientes exportados (SANTIN; BENEDETTI; REISSMANN, 2015), refletindo na forte 
redução da produtividade brasileira de erva-mate que, passou de 17,3 t/ha, em 1990, para 8,5 t/ha em 2014 (IBGE, 2015). Em Santa Catarina essa redução foi ainda mais intensa nesse período, com queda de $57 \%$, demonstrando que a cultura está em pleno declínio no Estado e que pode colocar em risco a economia de milhares de trabalhadores que dependem dessa cultura.

Uma das formas de substituir práticas produtivistas, manter os sistemas sustentáveis e agregar valor à produção é através da produção orgânica. Nesse sentido é que esse estudo foi desenvolvido, com o objetivo de avaliar o benefício da adubação orgânica para a sustentabilidade do sistema (solo e planta), na avaliação da produção da erva-mate.

\section{RESULTADOS E DISCUSSÕES}

Os resultados da produtividade de erva-mate encontram-se na Tabela 1. Observa-se que as propriedades apresentaram produtividade variável, porém em todas as propriedades, a maior incidência de luz e a adubação aumentaram a produtividade da erva-mate.

Tabela 1 - Produtividade de erva-mate nas diferentes propriedades, ambientes e adubações

\begin{tabular}{crrrrrrrrr}
\hline & \multicolumn{2}{c}{ Propriedade 1 } & \multicolumn{2}{c}{ Propriedade 2 } & \multicolumn{2}{c}{ Propriedade 3 } & \multicolumn{2}{c}{ Propriedade 4 } \\
\cline { 2 - 9 } Ambientes & S.A.* & C.A.** & \multicolumn{9}{c}{ S.A. } & C.A. & S.A. & C.A. & S.A. & C.A. \\
\cline { 2 - 9 } & \multicolumn{9}{c}{ Produtividade t/ha } \\
\hline Erval em Mata & 3,3 & 3,9 & 3,5 & 3,7 & 2,0 & 2,3 & 1,9 & 2,4 \\
Erval em Caíva & 3,6 & 4,6 & 6,1 & 10,1 & 2,6 & 3,1 & 5,4 & 7,1 \\
Erval em Caíva & 8,3 & 11,0 & 7,9 & 13,3 & 3,6 & 4,1 & 6,8 & 8,8 \\
Aberta & $\mathbf{5 , 1}$ & $\mathbf{6 , 5}$ & $\mathbf{6 , 0}$ & $\mathbf{9 , 0}$ & $\mathbf{2 , 7}$ & $\mathbf{3 , 2}$ & $\mathbf{4 , 7}$ & $\mathbf{6 , 1}$ \\
\hline MÉDIA & &
\end{tabular}

Obs.: Considerou-se a densidade de 1.500 plantas/ha. * S.A.: Sem adubação. ** C.A.: Com adubação

Fonte: Dados da Pesquisa (2016)

A maior produtividade de erva-mate no ambiente com maior incidência de luz era esperada, visto que a quantidade de biomassa produzida por uma espécie é limitada pela quantidade de energia radiante que sua folhagem pode interceptar (BLACK; ONG, 2000) assim como, pela quantidade de nutrientes que o solo é capaz de disponibilizar às plantas (EPSTEIN; BLOOM, 2004). Considerando que a erva-mate é uma espécie de sol, adaptada a sombra (RAKOCEVIC et al., 2011), quanto maior o sombreamento, menor será seu potencial fotossintético (RAKOCEVIC et al., 2008; RAKOCEVIC; MARTIM, 2011) e, consequentemente, menor será a produtividade de erva-mate, quando comparada a de cultivos com maior incidência de luz (RACHWAL et al., 2002). Mesmo que a erva-mate seja uma planta de sol, nos períodos mais quentes do verão um nível de sombra médio, pode atenuar a temperatura e favorecer seu crescimento. Assim o sombreamento em ervais é importante para a produção, além de ser uma forma de preservação da mata nativa e auxiliar na ciclagem de nutrientes.

A maior produtividade de erva-mate com a aplicação da adubação (Tabela 1) demonstra que a reserva natural de nutrientes do solo não é suficiente para suprir a necessidade da planta, principalmente em relação ao fósforo (Tabela 2). Isso é comprovado 
pela interpretação (CQFS, 2004) da análise de solo, onde demonstra que o fósforo no solo estava em nível muito baixo em todas as propriedades (Tabela 2).

Tabela 2 - Teor de fósforo, potássio, cálcio e magnésio disponível no solo nas diferentes propriedades.

\begin{tabular}{|c|c|c|c|c|}
\hline \multirow{2}{*}{ Propriedades } & Fósforo & Potássio & Cálcio & Magnésio \\
\hline & \multicolumn{2}{|c|}{----------- mg/dm ${ }^{3}$--------- } & \multicolumn{2}{|c|}{---------- $\mathrm{cmol}_{\mathrm{d}} / \mathrm{dm}^{3}$---------- } \\
\hline 1 & 2,00 & 124 & 0,77 & 0,30 \\
\hline 2 & 1,40 & 91 & 0,02 & 0,02 \\
\hline 3 & 3,70 & 188 & 2,27 & 1,04 \\
\hline 4 & 2,30 & 128 & 0,44 & 0,20 \\
\hline
\end{tabular}

Fonte: Dados da Pesquisa (2016)

$\mathrm{Na}$ Tabela 2, estão os resultados da disponibilidade de fósforo, potássio, cálcio e magnésio no solo antes da aplicação dos tratamentos. Nela, observa-se que a propriedade 3 apresentava os melhores níveis de nutrientes no solo, sendo que o potássio estava em nível considerado muito alto, cálcio e magnésio estavam em nível médio (CQFS, 2004). As demais propriedades apresentavam nível de $\mathrm{K}$ alto (propriedades 1 e 4) e médio (propriedade 2). $\mathrm{O}$ cálcio e magnésio estavam em nível baixo nas demais propriedades (CQFS, 2004).

Sabe-se que a erva-mate responde positivamente a adubação fosfatada (SANTIN et al., 2013; SANTIN et al., 2016), assim a dose de cama de frango foi adicionada para suprimento de fósforo. Desta forma, possivelmente, o fósforo presente no composto orgânico tenha sido fundamental para a resposta positiva da erva-mate a adubação neste trabalho.

$\mathrm{Na}$ tabela 3, observa-se que a adubação aplicada incrementou a produtividade média em 1,$4 ; 3,0 ; 0,5$ e 1,4 t/ha, respectivamente, para as propriedades $1,2,3$ e 4 . Como o gasto com adubação foi equivalente a $\mathrm{R} \$ 653,40 /$ ha e considerando o preço médio de $\mathrm{R} \$ 1,15 / \mathrm{kg}$ de erva-mate recebido ao produtor, observa-se que na maioria das propriedades o aumento da produção pagou o custo da adubação e ainda houve lucro. A exceção foi para a propriedade 3, a qual o custo da adubação superou em $\mathrm{R} \$ 78,40$ ao lucro obtido. A menor resposta dessa propriedade à adubação, está ligada ao fato de que os níveis de nutrientes no solo estavam mais altos em relação as outras propriedades. Isso demonstra que quando o solo não possui reserva adequada de nutrientes, a adubação é importante para aumentar a produtividade (consequentemente a renda do produtor) além de melhorar as condições do solo, tornando a atividade sustentável.

Tabela 3 - Incremento na produtividade média de erva-mate, custo da adubação, renda bruta e renda líquida em cada propriedade pesquisada.

\begin{tabular}{ccccc}
\hline \multirow{2}{*}{ Propriedades } & $\begin{array}{c}\text { Incremento } \\
\text { produtividade média }\end{array}$ & Custo adubação* & Renda Bruta** & Renda Líquida** $^{*}$ \\
\cline { 2 - 5 } & $\mathrm{kg} / \mathrm{ha}$ & 653,40 & $1.610,00$ & 956,60 \\
\hline 1 & 1.400 & 653,40 & $3.500,00$ & $2.846,60$ \\
3 & 3.000 & 653,40 & 575,00 & $-78,40$ \\
4 & 500 & 653,40 & $1.610,00$ & 956,60 \\
\hline
\end{tabular}

${ }^{*}$ Considerando $\mathrm{R} \$ 150,00 / \mathrm{t}$ de cama de aviário. ${ }^{* *}$ Considerando valor de $\mathrm{R} \$ 1,15 / \mathrm{kg}$ de erva-mate pago ao produtor.

Fonte: Dados da Pesquisa (2016) 
Inúmeros benefícios da erva-mate à saúde já foram comprovados (MEJÍA et al., 2010; LÜCKEMEYER et al., 2012). Esse fato serve de estímulo ao desenvolvimento de novos produtos oriundos da erva-mate, os quais são consumidos por pessoas que preferem produtos orgânicos e exigem que o produto seja oriundo de sistema de produção sustentável (IKEDA et al., 2010), além de poderem ter o reconhecimento como Indicação Geográfica (IG). Dallabrida et al. (2014) salienta que a erva-mate do Planalto Norte Catarinense apresenta potencial para ser inserida nesses moldes de produção. No entanto, o atual sistema de produção, sem preocupação com a sustentabilidade ambiental da cultura, poderá ser um impedimento para a obtenção de futura IG para a erva-mate. Os dados desse estudo indicam que o sistema produtivo atual da região ainda está muito atrelado ao extrativismo e não é sustentável ambientalmente, pois causa a exaustão nutricional do solo colocando em risco a manutenção desta atividade na região.

Ainda na década de 1980, Reissmann et al. (1985) já alertavam sobre a grande exportação de nutrientes pela erva-mate, devido ao fato do produto colhido ser predominantemente composto da folha (órgão que acumula maior quantidade de nutrientes), assim a reposição nutricional é necessária para evitar o empobrecimento do sítio. No entanto, esse alerta não foi atendido, culminando com a atual baixa disponibilidade de nutrientes nos solos onde é cultivada a erva-mate. Mesmo que em sistemas sombreados com mata nativa ocorra significativa ciclagem de nutrientes (SANTOS, 2009), os resultados positivos desse estudo demonstram que os nutrientes ciclados não são suficientes para manter o sistema produtivo. Esse fato pode ser comprovado pela degradação visual de outras espécies, como é o caso da araucária. Em 2014 Santa Catarina foi responsável por 35,8\% da produção brasileira de pinhão, no entanto, a produtividade de pinhão observada na região é considerada baixa (ZECHINI et al., 2012), fato ressaltado também por todos os produtores ${ }^{4}$ onde realizou-se os atuais experimentos.

A recuperação da fertilidade do solo para a produção de erva-mate faz com que indiretamente todo o sistema seja recuperado, não somente a erva-mate. Como a araucária e erva-mate ocorrem juntas (CORRÊA e KOCH, 2010), o aumento na produção de pinhão pode ser um efeito indireto da adubação da erva-mate. Nessa mesma perspectiva, a recuperação das pastagens, no sistema de caívas, muito comuns na região, também são favorecidas. Em estudo de Bona, Hanisch e Marques (2011), nessa região, observaram que com a introdução de insumos naturais como cama de aviário, fosfato natural e pó de basalto, se elevou a produção de pastagens em caívas de 2,0 t/ha para 4,5 t/ha de matéria seca. Esses autores salientam que a melhor alternativa para a conservação dos remanescentes florestais presentes nas áreas de caívas está diretamente ligada à atualização das estratégias de manejo desses sistemas tradicionais para que eles se mantenham viáveis economicamente, sendo que o manejo agroecológico do solo é capaz de compatibilizar a conservação ambiental com a adequada geração de renda.

Desta forma, a inserção de um manejo fácil e barato na recuperação da fertilidade do solo traz benefícios a todo o sistema, proporcionando maior renda ao produtor, além de ampliar e estimular as possibilidades de diversificação (exploração de erva-mate, pinhão e gado nessa região) de produção sustentável na propriedade.

${ }^{4}$ Comunicação pessoal. 
Sendo assim, observa-se grande potencial do PNC em inserir práticas agroecológicas e maximizar o potencial multifuncional da região, considerando os aspectos econômicos, ambientais e sociais de produção.

No entanto, observa-se que pelo fato das pesquisas com ênfase na nutrição de ervamate serem recentes, ressalta-se a importância da atualização dos agentes de assistência técnica, para instruir os produtores sobre a reposição nutricional. Isso tem potencial de favorecer a produção de forma sustentável e a permanência do produtor na atividade, trazendo benefícios indiretos à sociedade, principalmente pela conservação da FOM.

\section{CONSIDERAÇÕES FINAIS}

O cultivo sustentável de erva-mate, com reposição nutricional a partir de fontes orgânicas de nutrientes se apresenta com potencial para ser utilizado, uma vez que melhora as condições do sistema e aumenta a produção. Esses fatores estão em concordância com os preceitos da agroecologia e da produção orgânica, uma vez que o produtor pode utilizar os insumos produzidos na propriedade a fim de melhorar o sistema produtivo para geração de produto com valor agregado.

A ocorrência de erva-mate nas paisagens que compõe o Planalto Norte Catarinense, possibilita a obtenção de um produto diferenciado. Sua ocorrência em condições sombreadas (no sub bosque da Floresta Ombrófila Mista) permite que a mata seja preservada. Essa característica da região já a destaca de outras, onde normalmente as florestas são devastadas para ampliação de outros cultivos.

Outro fator de destaque é a ocorrência da ciclagem de nutrientes nessas condições. Esse fato possibilita que a erva-mate possa ser adubada através das outras espécies que ocorrem em sua volta. No entanto, o que se observa, mesmo em ervais com grandes intervalos de tempo entre colheitas, é que essa ciclagem normalmente não supre a necessidade nutricional do sistema (erva-mate e as outras espécies vegetais). Esse fato pode levar a insustentabilidade desse sistema.

A adição de insumos, os quais muitas vezes são produzidos na propriedade, como o esterco, se mostrou importante para reverter a atual situação dos ervais da região. A melhoria da produção de ervais nativos (utilizando fontes orgânicas) e consequentemente os níveis de nutrientes no solo (dados não demonstrados) são bases para atender aos preceitos da agroecologia, a qual preconiza a sustentabilidade social, ambiental e econômica.

Caso o produtor, não vislumbre retorno financeiro é difícil sua permanência na atividade, e ao tratarmos de erva-mate na região do Planalto Norte Catarinense, isso poderia resultar em diminuição da cobertura florestal da região, para inserção, nessas áreas de outras culturas agrícolas ou florestais.

A inserção de novas práticas, nem sempre são aceitas pelos produtores. Mas a possibilidade de termos um produto diferenciado, não só pela condição em que a erva-mate ocorre naturalmente, e sim aliada ao manejo em que os produtores insiram práticas de cultivo sustentáveis, poderiam, através da nossa maior riqueza natural, dar maior visibilidade e 
oportunidades à nossa região, inserindo-se no novo conceito de agricultura pós-produtivista, onde quem mais tem a ganhar é a sociedade.

Desta forma, conclui-se que a adoção de técnicas de adubação orgânica se mostrou viável para a produção de erva-mate nativa no sub-bosque da Floresta Ombrófila Mista na região do PNC, uma vez que melhorou a produtividade da erva-mate oportunizando dessa forma a diversificação da propriedade dentro dos preceitos agroecológicos e multifuncionais.

\section{AGRADECIMENTOS}

À Capes pela disponibilidade de bolsa, ao Instituto Federal de Educação, Ciência e Tecnologia de Santa Catarina (IFSC) pelo afastamento concedido para realização do estágio pós-doutoral. Ao programa de Mestrado em Desenvolvimento Regional, da Universidade do Contestado (UnC) campus Canoinhas pela oportunidade. Aos colegas pesquisadores Anésio da Cunha Marques e Ana Lúcia Hanisch pelo auxílio na indicação e escolha das propriedades as quais foram realizadas as pesquisas. E aos produtores Ancelmo Krzewinski, João Wardenski, Miguel Gurzynski e Paulo Bai por disponibilizarem suas propriedades para a realização da pesquisa, além de darem todo o suporte necessário.

\section{REFERÊNCIAS}

ALTIERI, M. Agroecologia: a dinâmica produtiva da agricultura sustentável. 5 ed. Editora da UFRGS, 2009. 1987.

Agroecology: the scientific basis of alternative agriculture. Boulder: Westview Press,

; NICHOLLS, C. I. O potencial Agroecológico dos Sistemas Agroflorestais na América Latina. Revista Agriculturas: experiências em Agroecologia, v. 8, n. 2, p.31-34, 2011.

ARMESTO LÓPEZ, X. A. Notas teóricas en torno al concepto de Postproductivismo Agrario. Investigaciones Geográficas, n. 36, p.137-156, 2005.

BAGGIO, A. J.; CARPANEZZI, A. A. Exportação de nutrientes na exploração de bracatingais. Boletim de Pesquisa Florestal, v. 34, p. 3-15, 1997.

BLACK, C.; ONG, C. Utilization of light and water in tropical agriculture. Agricultural and Forest Meteorology, v. 104, p. 25-47, 2000.

BONA, L. C.; HANISCH, A. L.; MARQUES, A. C. Melhoramento de caívas no Planalto Norte de Santa Catarina. Revista Agriculturas, v. 8, p.6-11, 2011.

CAPORAL, F. R; COSTABEBER, J. A. Agroecologia e extensão rural: contribuições para a promoção do desenvolvimento rural sustentável. 3.ed. Brasília: MDA/SAF/DATER, 2007.

DRd - Desenvolvimento Regional em debate (ISSNe 2237-9029) 
CARVALHO, P. E. R. Espécies arbóreas brasileiras. Brasília, DF: Embrapa Informação Tecnológica; Colombo: Embrapa Florestas, 2003. v. 1.

CAZELLA, A. A. A multifuncionalidade agrícola numa zona rural "desfavorecida": um estudo de caso na região serrana catarinense. In: CARNEIRO, M. J.; MALUF, R. S. (Orgs.). Para além da produção: multifuncionalidade e agricultura familiar. Rio de Janeiro: MAUAD, 2003, p. 28-44.

; BONNAL, P.; MALUF, R.S. Multifuncionalidade da agricultura familiar no Brasil e o enfoque da pesquisa. In: CAZELLA, A. A.; BONNAL, P.; MALUF, R. S. (Org.). Agricultura familiar: multifuncionalidade e desenvolvimento territorial no Brasil. Rio de Janeiro: Mauad X, 2009, p. 47-70.

; MATTEI, L. 2002: Multifuncionalidade agrícola e pluriatividade das famílias de agricultores: novas bases interpretativas para repensar o desenvolvimento rural. In: IV CONGRESSO SBS-IESA, Anais..., Santa Catarina, maio de 2002. 22p.

CHOUDHARY, M.; BAILEY, L. D.; GRANT, C. A. Review of the use of swine manure in crop production: effects on yield and composition and on soil and water quality. Waste Management and Reserch, v. 14, p. 581-595, 1996.

CORRÊA, M. C.; KOCH, Z. Araucária: a floresta do Brasil Meridional. Editora Olha Brasileiro Edições. 2010.

COSTA, A. M. et al. Potencial de recuperação física de um Latossolo vermelho, sob pastagem degradada, influenciado pela aplicação de cama de frango. Ciência Agrotecnológica, v. 33, p.1991-1998, 2009.

CQFS-RS/SC. Manual de adubação e calagem para os Estados do Rio Grande do Sul e Santa Catarina. 10. ed. Porto Alegre: SBCS, 2004.

DA CROCE, D. M. Cadeias produtivas do Estado de Santa Catarina: erva-mate. Florianópolis: Epagri, 2000. (Boletim técnico, 112).

DALLABRIDA, V. R.; BENEDETTI, E. L.; TOMPOROSKI, A. A. Do Produtivismo, ao Neoprodutivismo, para o Pós-Produtivismo no Espaço Rural: contextualização do debate teórico e práticas de gestão inovadoras em territórios catarinenses. In: $1^{\circ}$ Seminário Nacional de Desenvolvimento Regional: Sustentabilidade socioeconômica e ambiental no contexto regional, 1. mar./abr. 2016. Taquara. Anais... Taquara, 2016.

et al. Indicação geográfica da erva mate no território do contestado: reflexões e projeções. Desenvolvimento Regional em debate v. 4, n. 2, p. 44-77, 2014.

DEDECEK, R. A.; PHILIPOVSKY, J. F.; MEDRADO, M. J. S. Efeito da intensidade de movimentação do solo na produção de soja nas entrelinhas da erva-mate. Boletim de Pesquisa Florestal, v.47, p.3-18, 2003.

EIBL, B. et al. Agroforestry systems with Ilex paraguariensis (American holly or yerba mate) and native timber trees on small farms in Misiones, Argentina. Agroforestry Systems, v. 48, n. 1, p. 1-8, fev. 2000. 
ENGEL, V. L. Introdução aos Sistemas Agroflorestais. Botucatu. Fepaf. 1999.

EPSTEIN, E.; BLOOM, A. J. Nutrição mineral de plantas: princípios e perspectivas. 2. ed. Londrina: Planta, 2004.

EVANS, N.; MORRIS, C.; WINTER, M. Conceptualizing agriculture: a critique of postproductivism as the new orthodoxy. Progress in Human Geography, v. 26, p. 313-332, 2002.

FAO. Advancing agroforestry on the policy agenda: a guide for decision-makes. [S. I.]: Food and Agriculture Organization of the United Nations, 2013.

FAO/OMS. Directrices para la producción, elaboración, etiquetado y comercialización de alimentos producidos orgánicamente. Publicado por la Secretaría del Programa Conjunto FAO/OMS sobre Normas Alimentarias, FAO, Roma, 2001. Disponível em: $<$ http://www.fao.org/docrep/005/y2772s/y2772s02.htm\#bm02>. Acesso em: 21 mar. 2016.

HANISCH, A. L.; MARQUES, A. C.; BONA, L. C. Resposta de pastagens nativas à adubação com insumos agroecológicos em áreas de caíva no Planalto Norte Catarinense. R.E.V.I. Revista de Estudos do Vale do Iguaçu, v. 14. p. 139-148, 2009.

HANISCH, A. L. et al. Estrutura e composição florística de cindo áreas de caíva no Planalto Norte de Santa Catarina. Pesquisa Florestal Brasileira, v. 30, n. 64. p. 303-310, 2010.

IBGE (INSTITUTO BRASILEIRO DE GEOGRAFIA E ESTATÍSTICA). Produção Agrícola Municipal. Disponível em: $<$ http://www.sidra.ibge.gov.br/bda/tabela/ listabl.asp? $\mathrm{c}=106 \& \mathrm{z}=\mathrm{p} \& \mathrm{o}=28>$. Acesso em: 08 maio 2015 .

Censo 2010. Disponível em:

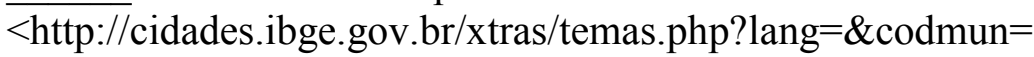
421830\&idtema=16\&search=santa-catarina $>$. Acesso em: 17 mar. 2016.

IKEDA, A. A.; MORAES, A.; MESQUITA, G. Considerações sobre tendências e oportunidades dos alimentos funcionais. Revista P \& D Engenharia de Produção, v. 8, p. 40-56, 2010.

ILBERY, B. W.; BOWLER, I. From agricultural productivism to postproductivism. In: ILBERY, B. (Ed.). The Geography of Rural Change. Longman, Harlow, p. 57-84, 1998.

KIEHL, E. J. Fertilizantes orgânicos. São Paulo: CERES, 1985. 429 p.

LAGIER, G. La aventura de la yerba mate más de cuatro siglos de historia. Buenos Aires, 2008. 196p.

LÜCKEMEYER, D. D. et al. Effects of Ilex paraguariensis A. St. Hil. (Yerba Mate) on herpes simplex virus types 1 and 2 replication. Phytotherapy Research, v. 26, p.535-540, 2012.

MAGALHÃES, R. Número de produtores orgânicos cresce 51,7\% em um ano. Ministério da Agricultura. 2015. Disponível em: <http://www.agricultura.gov.br/comunicacao/noticias/ 
2015/03/numero-de-produtores-organicos-cresce-51 porcento-em-um-ano $>$. Acesso em: 20 mar. 2016.

MAIA, A. G.; BUAINAIN, A. M. O novo mapa da população rural brasileira. Revista Franco brasileira de geografia, n. 25, 2015. Disponível em:

$<$ https://confins.revues.org/10548?lang=pt >. Acesso em: 22 mar. 2016.

MALUF, R. S. O enfoque da multifuncionalidade da agricultura: aspectos analíticos e questões de pesquisa. In: LIMA, D.M.; WILKINSON, J. (Org.) Inovação nas tradições da agricultura familiar. Brasília: CNPq/Paralelo 15, 2002, p. 301-328.

MARQUES, A. C. as paisagens do mate e a conservação socioambiental: um estudo junto aos agricultores familiares do Planalto Norte Catarinense. Curitiba, Tese (Doutorado em Meio Ambiente e Desenvolvimento) - UFPR, 2014.

MARSDEN, T.; LOWE, P.; WHATMORE, S. Rural restructuring: global processes and their responses (critical perspectives on rural change). Londres: David Fulton Publishes, 1990.

MARTINS, C. Plantas medicinais: limites e possibilidades para o desenvolvimento do município de Canoinhas (SC). Canoinhas, Dissertação (Mestrado em Desenvolvimento Regional) - UnC, 2015.

MAY, P. H.; TROVATTO, C. M. M. Manual Agroflorestal para a Mata Atlântica.

Brasília: Ministério do desenvolvimento Agrário, Secretaria da Agricultura familiar, 2008.

MEJÍA, E. G. et al. Yerba mate tea (Ilex paraguariensis): Phenolics, antioxidant capacity and in vitro inhibition of colon cancer cell proliferation. Journal of Functional Foods, v.2, p.2334, 2010.

MIOR, L.C. Agricultura familiar, agroindústria e desenvolvimento territorial. In: VIEIRA, P. F. et al. Desenvolvimento Territorial Sustentável no Brasil. Subsídios para uma política de fomento. Florianópolis: APED: Secco. 2010, p. 235-257.

MONTECHIESI, R. Yerba mate, câmbios em la producción, no em la actividad. Posadas, 2008.

NAIR, P. K. R. Perspective The coming of age of agroforestry. Journal of the Science of Food and Agriculture. v. 87, p.1613-1619, 2007.

ONU- Organização das Nações Unidas. Centro regional de Informação das Nações Unidas.

Relatório da ONU mostra população mundial cada vez mais urbanizada, mais de metade vive em zonas urbanizadas ao que se podem juntar 2,5 mil milhões em 2050. Disponível em: <http://www.unric.org/pt/actualidade/31537-relatorio-da-onu-mostrapopulacao-mundial-cada-vez-mais-urbanizada-mais-de-metade-vive-em-zonas-urbanizadasao-que-se-podem-juntar-25-mil-milhoes-em-2050>. Acesso em: 22 mar. 2016.

PAWLOWYTSCH, P. W. M. A pobreza no Planalto Norte Catarinense: representações sociais e implicações no desenvolvimento regional. Canoinhas, Dissertação (Mestrado em Desenvolvimento Regional) - UnC, 2014. 
PENTEADO, S. R. Agricultura orgânica. (Série Produtor Rural, Edição Especial). Piracicaba: ESALQ. 2001.

PETRENTCHUK, L. W. Possibilidades e Desafios do Manejo de Fragmentos de Floresta Ombrófila Mista como Alternativa de Desenvolvimento: Um estudo com base na realidade socioeconômica ambiental em Canoinhas (SC). Canoinhas, Dissertação (Mestrado em Desenvolvimento Regional) - UnC, 2015.

PICCOLO, G. A.; GALANTINI, J. A.; ROSELL, R. A. Organic carbon fractions in a yerba mate plantation on a subtropical Kandihumult of Argentina. Geoderma, v. 123, p. 333-341, 2004.

RACHWAL, M. F. G. et al. Influência da luminosidade sobre a produção de massa foliar e teores de macronutrientes, fenóis totais, cafeína e teobromina em folhas de erva-mate. Colombo: Embrapa Florestas, 2002. (Embrapa Florestas. Comunicado técnico, 81).

RAKOCEVIC, M. et al. Distribuição de estômatos em folhas de diferentes idades de ervamate cultivada em monocultura e sub-bosque. In: CONGRESO SUDAMERICANO DE LA YERBA MATE, 5., Posadas, 2011. Actas... Posadas: INYM/ INTA/INaM, 2011. p. 45-50.

; MARTIM, S. F. Time series in analysis of yerba-mate biennial growth modified by environment. International Journal of Biometeorology, v. 55, n. 2, p. 161-171, 2011.

et al. Intensity of bitterness of processed yerba mate leaves originated in two contrasted light environments. Brazilian Archives of Biology and Technology, v. 51, n. 3, p. 569-579, 2008.

; MEDRADO, M. J. S.; TAKAKI, M. Aspectos fotomorfogenéticos de plantas jovens de erva-mate. In: CONGRESSO SUL-AMERICANO DA ERVA-MATE, 3., Chapecó, 2003. Anais... Chapecó: EPAGRI, 2003. 5 p. CD-ROM.

REIS, M. G. F.; BARROS, N. F. Ciclagem de nutrientes em plantios de eucalipto. In: BARROS, N. F.; NOVAIS, R. F. Relação Solo-eucalipto. Viçosa: Folha de Viçosa; 1990. p. 265-302.

REISSMANN, C. B. et al. Avaliação da exportação de macronutrientes pela exportação da erva-mate. In: SEMINÁRIO SOBRE ATUALIDADES E PERSPECTIVAS FLORESTAIS, 10., 1983, Curitiba. Silvicultura da erva-mate (Ilex paraguariensis St. Hil). Curitiba: EMBRAPA-CNPF, 1985. p. 128-139 (EMBRAPA-CNPF. Documentos 15).

RÉMY, J. A agricultura multifuncional, a serviço do desenvolvimento sustentável? In: VIEIRA, P. F. et al. Desenvolvimento Territorial Sustentável no Brasil. Subsídios para uma política de fomento. Florianópolis: APED: Secco. 2010, p. 225-233.

SABOURIN, E. Multifuncionalidade da agricultura e manejo de recursos naturais:

alternativas a partir do caso do semi-árido brasileiro. Tempo da Ciência, v. 15, n. 29. p. 9-27, 2008. 
SANTA CATARINA (Estado). Secretaria de Estado do Planejamento, Orçamento e Gestão.

Estudo diagnóstico da Regional Canoinhas. Programa das Nações Unidas para o Desenvolvimento - PNUD, projeto BRA 03/008. Canoinhas, 2005. Disponível em: $<$ http://www.spg.sc.gov.br/proj_parcerias/meu_lugar/sdr_canoinhas.php>. Acesso em: 22 mar. 2016.

SANTIN, D. et al.. Manejo de colheita e adubação fosfatada na cultura da erva-mate (Ilex paraguariensis) em fase de produção. Ciência Florestal, 2016. (No prelo)

. et al. Crescimento e nutrição de erva-mate influenciados pela adubação NPK.

Ciência Florestal, v. 23, n. 2, p. 363-375, 2013.

SANTIN, D.; BENEDETTI, E. L.; REISSMANN, C. B. Nutrição e recomendação de adubação e calcário para a cultura da erva-mate. In: WENDLING, I.; SANTIN, D.

Propagação e nutrição de erva-mate. Brasília, DF: Embrapa, 2015, p. 99-195.

SANTOS, S. C. L. Avaliação comparativa entre sistema agroflorestal com erva-mate e fragmento de floresta ombrófila mista quanto à fitossociologia, parâmetros químicos e físicos do solo e ciclagem de nutrientes. Dissertação (Mestrado em Ciência do Solo) UFPR, Curitiba, 2009.

SCHIMIDT, W. Conversão à agricultura orgânica e multifuncionalidade: o caso das Encostas da Serra Geral (SC). In: CARNEIRO, M. J.; MALUF, R. S. (Orgs.) Para além da produção: multifuncionalidade e agricultura familiar. Rio de Janeiro: MUAD, 2003, p. 44-60.

SCOLARO, T. L.; TABASCO, J. J. P. Usos do solo e Desenvolvimento Regional: um estudo em municípios do Planalto Norte Catarinense. Canoinhas: Universidade do Contestado, 2016 (no prelo).

SOUZA, A. M. Dos ervais ao mate: possibilidades de revalorização dos tradicionais processos de produção e de transformação de erva-mate no Planalto Norte-Catarinense. Florianópolis, Dissertação (Mestrado em Agroecossistemas) - UFSC, 1998.

VIEIRA, P. F. et al. Potencialidades e obstáculos à construção de territórios sustentáveis no Estado de Santa Catarina. Política \& Sociedade, n. 14, p. 335-380, 2009.

WILLER, H.; LERNOUD, J. The World of Organic Agriculture. Statistics and Emerging Trends. International Federation of Organic Agriculture Movements (IFOAM) \& Research Institute of Organic Agriculture (FiBL). 2014. Disponível em: $<$ https://shop.fibl.org/de/ artikel/c/statistik/p/1636-organic-world-2014.html>. Acesso em: 18 mar. 2016.

WILSON, G. A. From productivism to post-productivism... and back again? Exploring the (un)changed natural and mental landscapes of European agriculture. Transactions of the Institute of British Geographers, n. 26, p. 77-102, 2001.

YAMADA, M.; GHOLZ, H. L. An evaluation of agroforestry systems as a rural development option for the Brazilian Amazon. Agroforestry Systems, v. 55, p. 81-87, 2002. 
ZECHINI, A. A. et al. Produção, Comercialização e Identificação de Variedades de Pinhão no Entorno da Floresta Nacional de Três Barras - SC. Biodiversidade Brasileira, v.2, p.74-82, 2012.

ZOLDAN, P. C.; MIOR, L. C. Produção orgânica na agricultura familiar de Santa Catarina. Florianópolis: Epagri, 2012. (Epagri. Documentos, 239).

Artigo recebido em: 19/06/2016

Artigo aprovado em: 13/07/2016 